\title{
The morphometric measurements of the temporomandibular joint
}

\author{
Daniela Pita de Melo $^{1}$, Diego F. Bezerra Silva ${ }^{1}$, Paulo S. F. Campos ${ }^{2}$, Janaína Araújo Dantas ${ }^{3}$ \\ ${ }^{1}$ Department of Oral Diagnosis, State University of Paraíba, Campina Grande, Brazil; ${ }^{2}$ Department of Radiology, School of Dentistry, Federal \\ University of Bahia, Salvador, Brazil; ${ }^{3}$ Faculty UNIME Salvador, Salvador, Brazil \\ Contributions: (I) Conception and design: DP de Melo, JA Dantas; (II) Administrative support: DP de Melo, PSF Campos; (III) Provision of study \\ materials or patients: DFB Silva, PSF Campos; (IV) Collection and assembly of data: DP de Melo, JA Dantas, DFB Silva; (V) Data analysis and \\ interpretation: DP de Melo, JA Dantas, DFB Silva; (VI) Manuscript writing: All authors; (VII) Final approval of manuscript: All authors. \\ Correspondence to: Daniela Pita de Melo. Rua Baraúnas, 351 - Bairro Universitário Campina Grande-PB, CEP 58429-500, Brazil. \\ Email: danipita@gmail.com.
}

\begin{abstract}
The temporomandibular joint (TMJ) is a synovial joint classified for its surface shape and complex biaxial movements as a ginglimoartrodial joint and presents the widest joint range of movements when compared with the other joints of the human body. The complexity of TMJ morphology has driven researchers to investigate its morphometric features and their relationship with temporomandibular disorders (TMD). Therefore, the knowledge of morphological and morphometric data of each bone component of the TMJ is of paramount importance for identifying bone changes related to the TMJ, in the presence of TMD in symptomatic and non-symptomatic patients. This literature review aims to assess previous studies on the TMJ bone structures morphological and morphometric findings and discuss what these findings implicate on TMDs. The assessed studies varied in sample size and categorization, and measurement methodologies [measurements done directly on specimen, image modality-computed tomography (CT), cone beam computed tomography (CBCT), magnetic resonance imaging (MRI)], study method of choice and main morphometric points). Morphometric measurements of the condyle, articular fossa and articular eminence were assessed in different planes (axial, sagittal and coronal). Male patients present higher condyle and glenoid fossa morphometric measurement values than female patients, however, when considering the articular eminence's inclination/steepness the gender difference is not conclusive. When more than one image method was assessed, a slight difference has been observed between the image modalities. It can be concluded that large, paired samples and longitudinal studies using non-ionizing images are still needed to assess the TMJ morphometric values and its association with internal disorders, age, ethnicity, and gender.
\end{abstract}

Keywords: Temporomandibular Joint (TMJ); anatomy; radiology

Received: 30 September 2020; Accepted: 26 March 2021; Published: 10 June 2021.

doi: $10.21037 /$ fomm-20-63

View this article at: http://dx.doi.org/10.21037/fomm-20-63

\section{Introduction}

The temporomandibular joint (TMJ) is a synovial joint classified for its surface shape and complex biaxial movements as a ginglimoartrodial joint due to its rotational movement inside the glenoid fossae and its translational movement along the articular eminence during mouth opening (1-3). Therefore, the TMJ presents the widest joint range of movements when compared with the other joints of the human body. Another peculiarity of the TMJ is that it is one of few synovial joints that are covered with fibrocartilage, not hyaline cartilage $(1,4)$. Thus, the TMJ is a double synovial joint of bilateral unique bone working as one functional unit (3).

The complexity of TMJ morphology has driven researchers to investigate its morphologic and morphometric features

$\wedge$ ORCID: 0000-0002-6477-6997 
and their relationship with temporomandibular disorders (TMD) (5). Various image modalities have been used to assess TMJ's morphology, i.e., magnetic resonance imaging (MRI), computed tomography (CT), cone beam computed tomography (CBCT), ultrasound (US) and panoramic radiography $(\mathrm{PR})(2,5-15)$. Conventional bidimensional images of the TMJ present distortions and are not acceptable for morphometric assessments, while US images are not usually used on morphometric analysis. CT and CBCT images are known as the best modalities to assess bone structures, while MRI is vastly used to assess the TMJ as it presents great contrast for soft tissue analysis and presents acceptable images of bone structures (12).

One of the main advantages of MRI while assessing the TMJ is that this exam shows a clear image of the TMJ disc, enabling the detection of disc displacements and the assessment of disc abnormalities $(16,17)$. Another advantage of MRI is that it is a high-quality non-ionizing image modality (16).

The main question that still has not been answered by the literature is if the anatomy of the TMJ leads to TMD or the presence of TMD shapes the anatomy of the TMJ. What is clear is that morphology and function cannot be dissociated. Therefore, this paper aims to describe the anatomy of the TMJ and its morphometric varieties.

\section{Literature review}

When reviewing the previously published papers on morphometric assessment of the TMJ, the different sample sizes are a point to notice. Sample size calculation is important for methodological and ethical reasons. Small samples undermine the internal and external validity of a study and large samples tend to transform small differences into statistically significant differences (18). When assessing the TMJ, each patient counts as two TMJs and sample sizes of the assessed literature varied from 11 to $800(5,8,13,14,19-21)$.

Scientific evidence suggests that the displacement of the articular disc leads to degenerative changes of the disc and articular surfaces $(5,22,23)$. However, previous studies suggest that the TMJ anatomy, especially the articular eminence, influences the development of TMD $(19,24)$. In addition, degenerative changes in the TMJ caused by trauma, female hormones, and changes in the extracellular matrix (7) may lead to changes in the morphology and morphometry of the bone components of the TMJ.

Therefore, the knowledge of morphological and morphometric data of each bone component of the TMJ is of paramount importance for identifying bone changes related to the TMJ, in the presence of TMD in symptomatic and non-symptomatic patients. The main findings in patients with TMD are changes in the masticatory muscles and internal disorders of articular disc (mainly disc displacement), condyle, articular fossa, and articular eminence.

To assess the previous literature on TMJ morphometry, each bone component will be reported separately.

\section{Bone components of the TMF}

\section{Condyle}

The mandibular condyle has an ellipsoid shape and presents on average a medio-lateral dimension of $17.04 \mathrm{~mm}$ to $20 \mathrm{~mm}$, while its average anteroposterior dimension varies from $5.12 \mathrm{~mm}$ to $9.6 \mathrm{~mm}(10,11,14,15,19,25)$. In the axial view, the condyles show unaligned poles which present their major axis not perpendicularly aligned with the median sagittal plane; hence, the condyle's lateral pole is positioned anteriorly to the medial pole. Therefore, the extension of the major condyle axis forms an angle of approximately $18.3^{\circ} \pm 8.3^{\circ}$ to $24.36^{\circ} \pm 6.35^{\circ}$ with the coronal plane, denominated the horizontal angle of the condyle $(26,27)$ (Figure 1).

The condyle has been morphologically assessed in the axial view as presenting five different shapes according to their anterior and posterior forms: flat/convex, biconvex, concave/convex, flat, and biconcave (28). Although the anterior side concave/posterior side convex condyle shape seems to be more prevalent when disc displacement is present, it is still a controversial finding (29).

In the axial view, the condyle has been assessed taking in consideration four main morphometric points: condyle medial pole, condyle lateral pole, condyle anterior vertex and condyle posterior vertex. From these points the following measurements were obtained: major axis length (the distance from the condylar medial pole to its lateral pole); and the minor axis length (the distance from the most anterior point of the condyle to the most posterior point of the condyle) (Figure 2) (14).

In the coronal view, the condyle has been previously described presenting the following shapes: convex, flat, angled and round. Round shape condyles are more common in children (6). Convex and angled morphologies are more associated to disc displacement; however, TMD patients' condyle may present a deformed morphology (29).

Morphometric studies have used the following guiding anatomical reference points to assess the condyle in the coronal view: the most superior point of the mandibular 

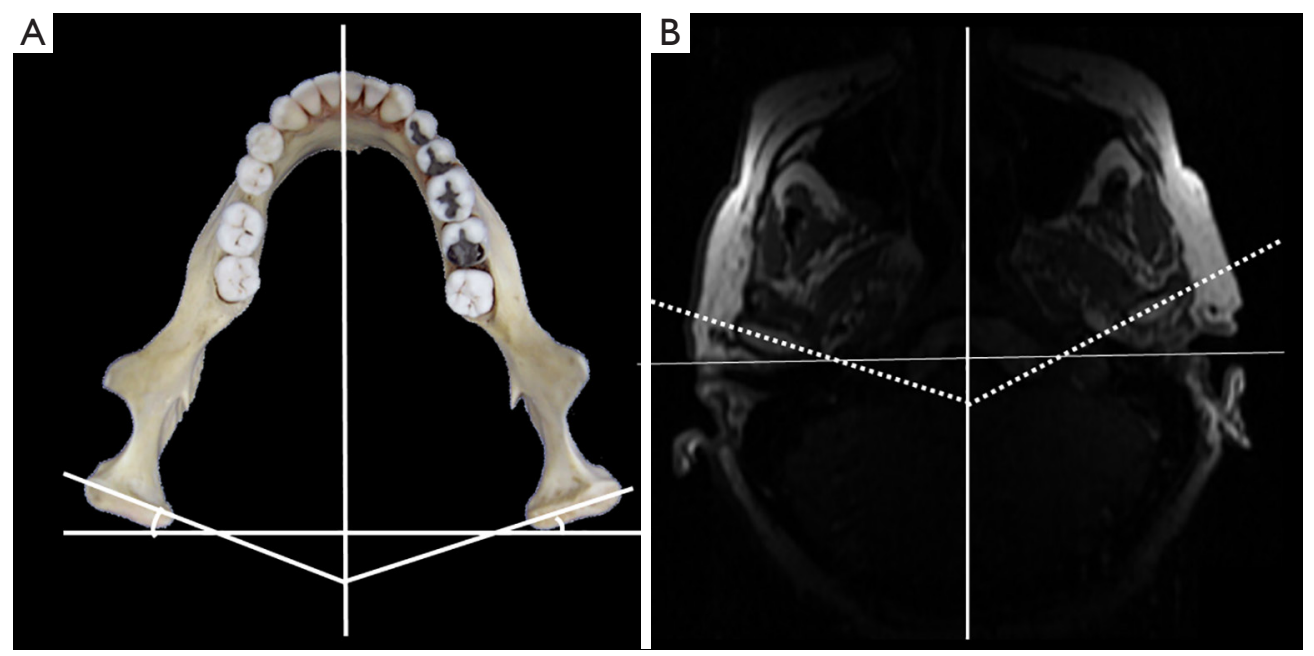

Figure 1 The horizontal angle of the condyle on a mandible (A) and on an MRI (B).
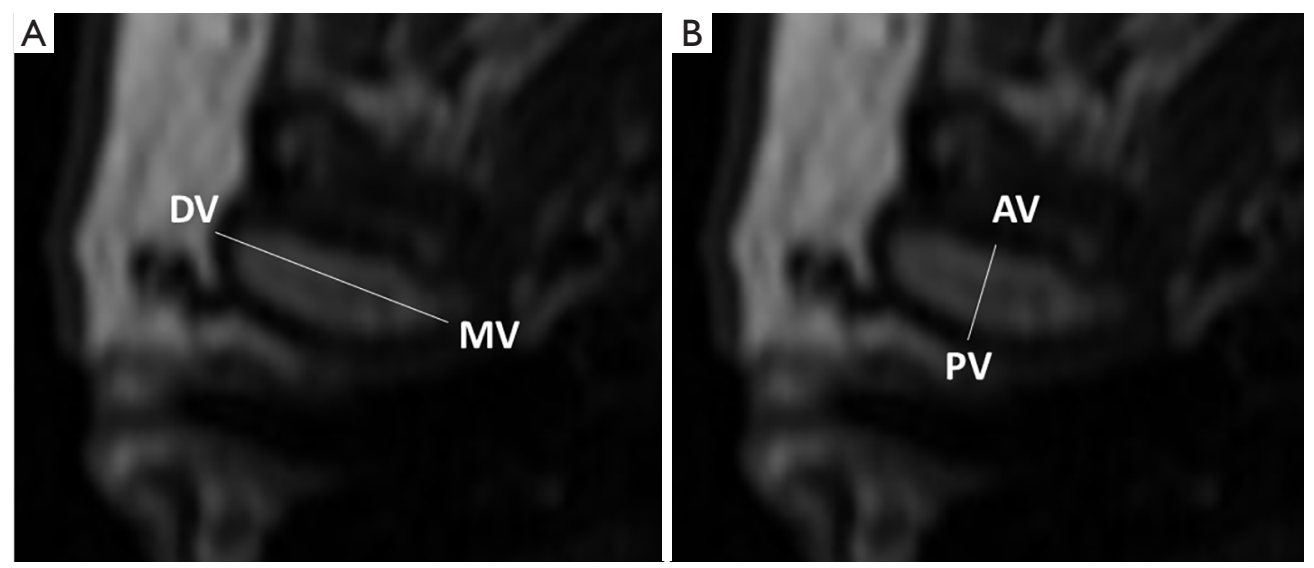

Figure 2 Axial MRI. (A) Axial major axis length: Distance between the distal vertex (DV) to the mesial vertex (MV) of the condyle; (B) axial minor axis length: distance between the anterior vertex (AV) to the posterior vertex (PV) of the condyle.

fossa, the most superior point of the condyle (condyle superior vertex), the roof of the mandibular fossa and the medial and lateral poles of the condyle $(5,14)$. With these morphometric points, condylar height (the distance from the roof of the mandibular fossa to the condyle superior vertex); lingual length (the distance from the mandibular fossa) to the condyle medial pole); vestibular length (the distance from the wall of the mandibular fossa) to the lateral pole of the condyle) were determined (14). The condyle major axis can also be assessed from the coronal view of the condyle using the medial and lateral poles as reference points (Figure 3).

Torres et al. (10), established and assessed the condylar medial angle by assessing the internal angle between the long axis and the neck of the condyle and correlated the obtained values with disc displacement; however, there was no association between this angle and the presence or type of disc displacement.

In the sagittal view, the condyle has been assessed previously for its anteroposterior width/minor axis length (distance between the most anterior point and the posteriormost point of the condyle) (13), also named as condyle thickness by Torres et al. (10); and the anterior condylar angle (the angle between the neck and head of the condyle) (10). The condyle diameter was established by Peroz et al. (8) based on the diameter of a circle, with the central point of this circle represented by the center of the condyle (Figure 4).

Condyle morphometric measures have varied in previous studies according to the image modality (CT, 

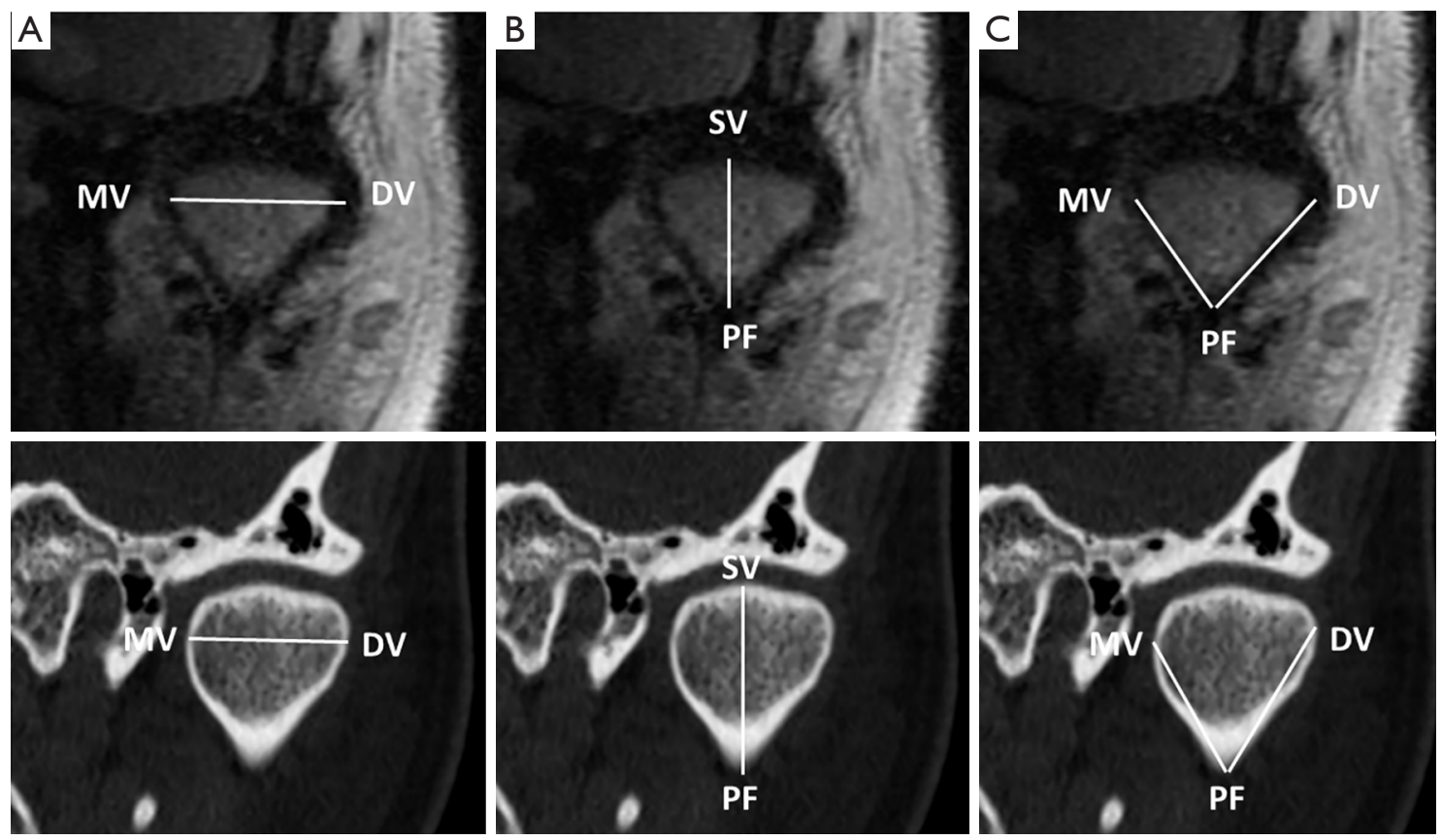

Figure 3 Medial and lateral poles as reference points in the coronal view to assess the following morphometric measurements. (A) The major axis length of the condyle; (B) condylar height; (C) the lingual length and the vestibular length of the condyle. DV, distal vertex; MV, mesial vertex; $\mathrm{AV}$, anterior vertex; $\mathrm{PF}$, pterygoid fovea; $\mathrm{SV}$, superior vertex.
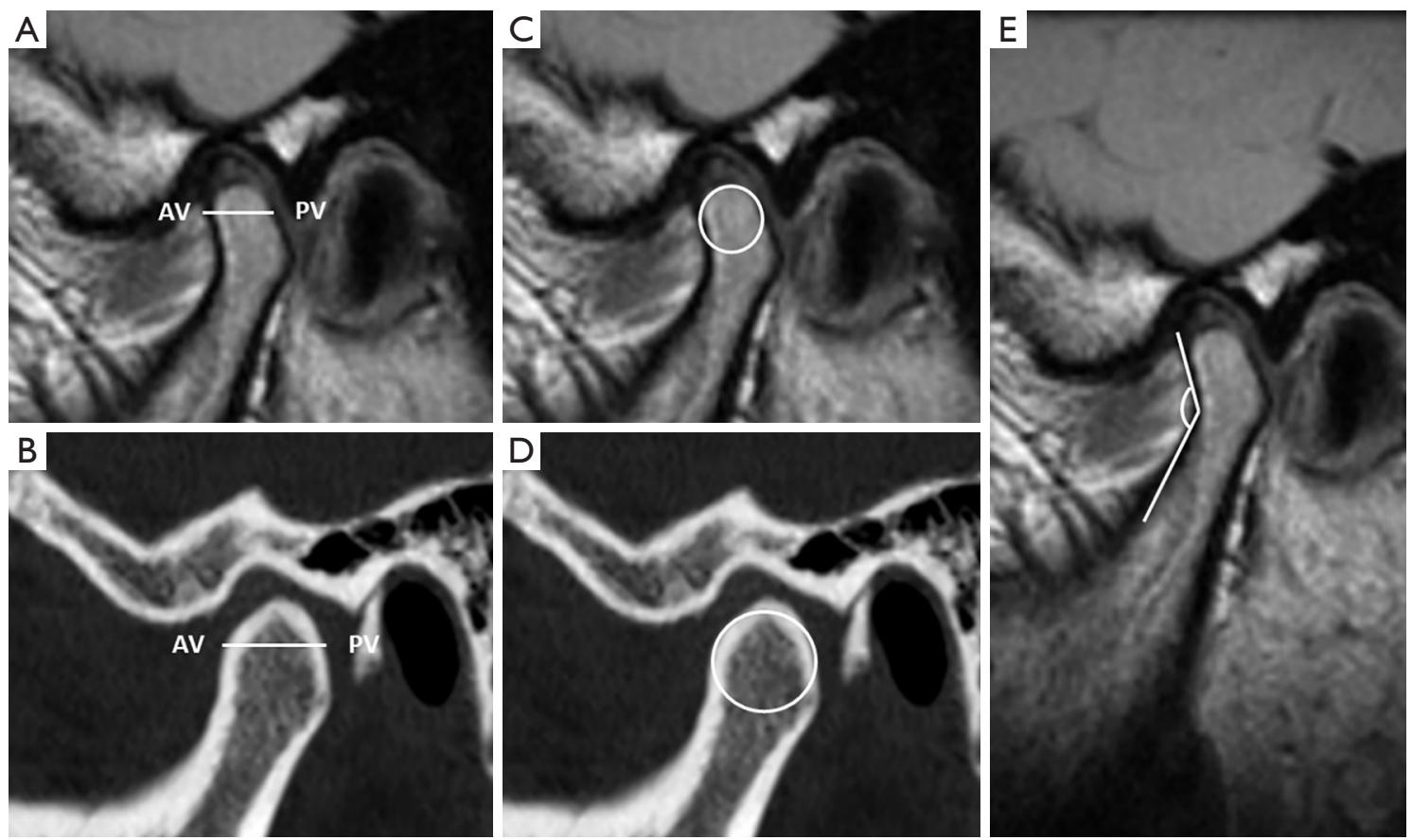

Figure 4 Condyle sagittal morphometric assessment of the following morphometric measurements: (A) anteroposterior condylar width on MRI; (B) anteroposterior condylar width on CT; (C) condyle diameter on MRI; (D) condyle diameter on CT; (E) anterior condylar angle on MRI. AV, anterior vertex; PV, posterior vertex. 
Table 1 Summary of morphometric measures of the condyle assessed in previous studies

\begin{tabular}{|c|c|c|c|c|c|c|c|c|c|c|c|}
\hline \multirow{4}{*}{$\begin{array}{l}\text { Previous } \\
\text { studies }\end{array}$} & \multicolumn{11}{|c|}{ Articular Condyle } \\
\hline & \multicolumn{2}{|c|}{ Methodology } & \multicolumn{3}{|c|}{ Condyle major axis (mm) } & \multicolumn{3}{|c|}{ Condyle minor axis (mm) } & \multicolumn{3}{|c|}{ Condyle diameter $(\mathrm{mm})$} \\
\hline & \multirow{2}{*}{$\begin{array}{c}\text { Image } \\
\text { Modality }\end{array}$} & \multirow{2}{*}{$\frac{\text { TMJ }}{\text { Sample size }}$} & \multicolumn{2}{|c|}{ Sex } & \multirow{2}{*}{$\frac{\text { Both }}{\text { Genders }}$} & \multicolumn{2}{|c|}{ Sex } & \multirow{2}{*}{$\frac{\text { Both }}{\text { Genders }}$} & \multicolumn{2}{|c|}{ Sex } & \multirow{2}{*}{$\frac{\text { Both }}{\text { Genders }}$} \\
\hline & & & Male & Female & & Male & Female & & Male & Female & \\
\hline Derwich 2020 & СВCT & 210 & - & - & 19 & - & - & 6.8 & - & - & - \\
\hline Coombs 2019 & $\begin{array}{c}\text { CBCT/MRI/ } \\
\text { physical } \\
\text { measurements }\end{array}$ & 11 & - & - & 20.6/19.8/20.2 & - & - & 8.3/7.9/9.6 & - & - & - \\
\hline de Pontes 2019 & MRI & 186 & - & - & - & 6.83 & 6.72 & - & - & - & - \\
\hline Peroz 2011 & MRI & 78 & - & - & - & - & - & - & 7.3 & 6.7 & - \\
\hline
\end{tabular}

Table data were extracted from previously published studies referenced in the table first column. TMJ, temporomandibular joint; CBCT, cone beam computed tomography.

CBCT, MRI) or study method of choice, which could be based on physical measurements on a set of mandibles or a set of images from different study groups (gender, age, and ethnicity). When more than one image method was assessed, a slight difference was observed between the image modalities. The morphometric measures have been assessed as overall measures or divided by gender, and male patients present higher values for all previously assessed condyle measurements (Table 1).

\section{Articular component of the temporal bone-articular fossa}

The articular fossa is the articular component of the squamous portion of the temporal bone. The articular fossa presents an average depth of $4.73 \mathrm{~mm}$ for male patients and $4.34 \mathrm{~mm}$ for female patients, using the vertex of the articular eminence as reference point (13). The petrotympanic fissure limits the articular fossa posteriorly. Behind the petrotympanic fissure is the anterior wall of the tympanic portion of the temporal bone, and medially limiting the mandibular fossa is the sphenoidal spine (spina angularis). The anterior portion of the mandibular fossa continues with the posterior portion of the articular eminence. Laterally to the articular eminence is the root of the zygomatic process of the temporal bone which, with the temporal process of the zygomatic bone, forms the zygomatic arch.
Morphologically the articular fossa has been classified in the sagittal view as concave, angled, or flat, based on the classification of Oberg et al. (5,30). Oberg et al. (30) showed that the incidence of fossa morphologies in autopsy subjects was $61 \%$ for concave, $4 \%$ for angled and $23.5 \%$ for flat. Similarly, Matsumoto et al. (31) found a higher prevalence of concave shape, followed by angled and flat shape.

Morphometric assessments of the articular fossa have been conducted in the sagittal view, and the following parameters have been assessed: glenoid fossa width (the distance between the post-glenoid process and the articular eminence vertex); glenoid fossa depth (the distance between the highest point of the fossa and the line between the postglenoid process and the articular eminence vertex); and glenoid fossa roof thickness (the thickness thinnest bone forming the roof of the glenoid fossa) (Figure 5) $(25,32)$.

The glenoid fossa has been assessed for its depth, length, and roof thickness. Morphometric values can vary according to the image modality of choice; however, there a few studies using other images modalities besides CBCT. Male patients present higher glenoid fossa morphometric values than female patients (Table 2).

\section{Articular eminence}

The articular eminence is covered by a very thin cortical 

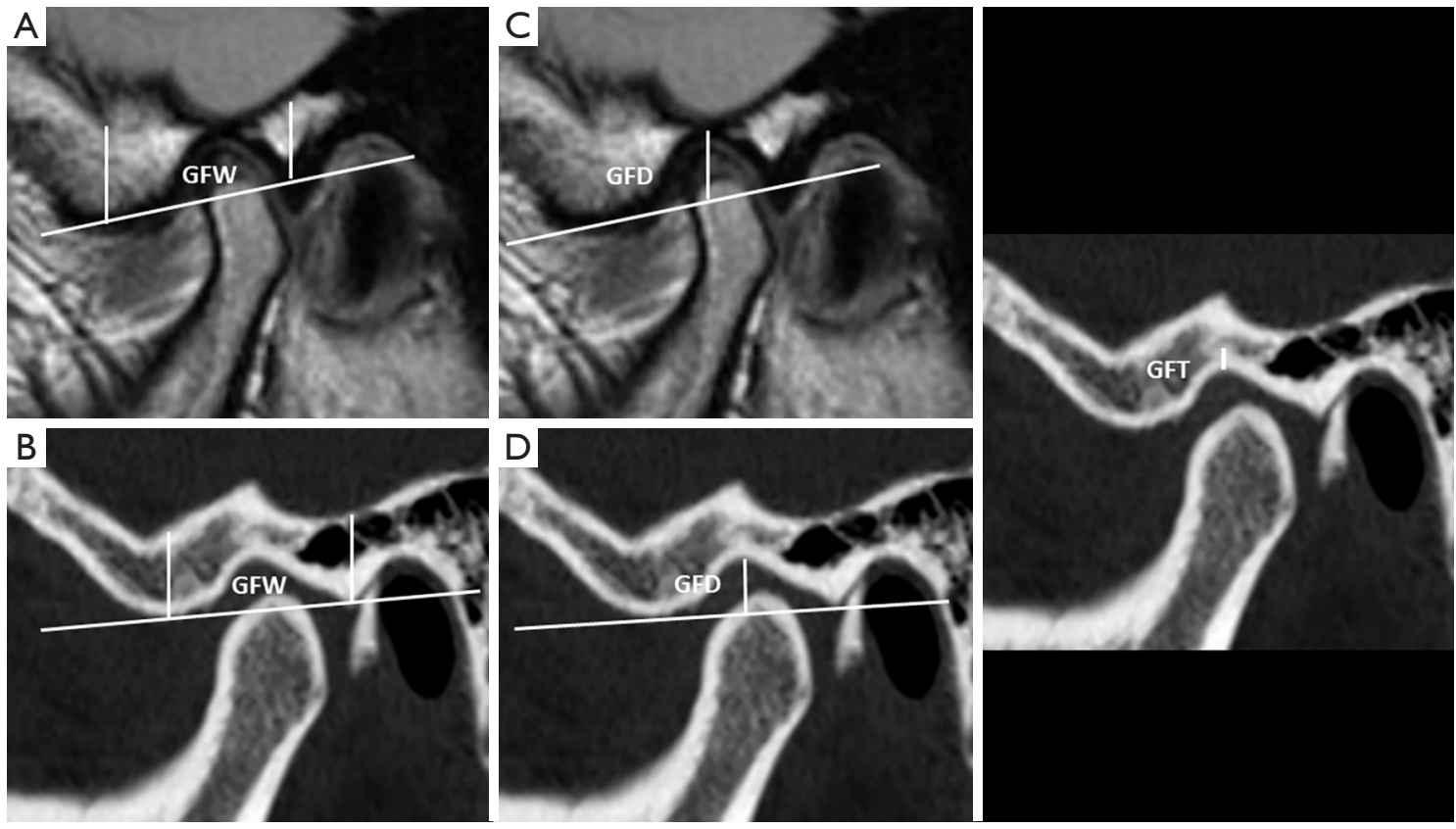

Figure 5 Morphometric assessments of the articular fossa in the sagittal view to assess the following morphometric measurements: (A) GFW on MRI; (B) GFW on CT; (C) GFD on MRI; (D) GFD on CT. GFW, glenoid fossa width; GFD, glenoid fossa depth; GFT, glenoid fossa thickness.

Table 2 Summary of morphometric measures done by previous studies for the glenoid fossa

\begin{tabular}{|c|c|c|c|c|c|c|c|c|c|c|c|}
\hline \multirow{4}{*}{$\begin{array}{l}\text { Previous } \\
\text { studies }\end{array}$} & \multicolumn{11}{|c|}{ Glenoid fossa } \\
\hline & \multicolumn{2}{|c|}{ Methodology } & \multicolumn{3}{|c|}{ Glenoid fossa depth (mm) } & \multicolumn{3}{|c|}{ Glenoid fossa length (mm) } & \multicolumn{3}{|c|}{ Glenoid fossa roof thickness $(\mathrm{mm})$} \\
\hline & \multirow{2}{*}{$\frac{\text { Image }}{\text { Modality }}$} & \multirow{2}{*}{$\frac{\text { TMJ }}{\text { Sample Size }}$} & \multicolumn{2}{|c|}{ Sex } & \multirow{2}{*}{$\frac{\text { Both }}{\text { Genders }}$} & \multicolumn{2}{|c|}{ Sex } & \multirow{2}{*}{$\frac{\text { Both }}{\text { Genders }}$} & \multicolumn{2}{|c|}{ Sex } & \multirow{2}{*}{$\frac{\text { Both }}{\text { Genders }}$} \\
\hline & & & Male & Female & & Male & Female & & Male & Female & \\
\hline Derwich 2020 & СВСТ & 210 & - & - & 9.8 & - & - & 20.5 & - & - & - \\
\hline Ejima 2013 & $\mathrm{CBCT}$ & 144 & - & - & - & - & - & - & 1.06 & 0.93 & 1.00 \\
\hline Peroz 2011 & MRI & 78 & - & - & - & - & - & - & 7.3 & 6.7 & - \\
\hline
\end{tabular}

Table data were extracted from previously published studies referenced in the table first column. TMJ, temporomandibular joint; CBCT, cone beam computed tomography; MRI, magnetic resonance imaging.

bone and is filled with trabecular bone comparable to the head of the humerus and femur. These morphological characteristics seem to be an adaptation to the functional pressures caused by joint movement (33). The morphology of the articular eminence has been previously classified into four shapes: box, sigmoid, flattened or deformed $(5,34,35)$. The articular eminence height has been measured as the distance between the lowest point of the articular eminence and the highest point of the fossa. The inclination of the articular eminence is defined as the angle formed by a line from the articular eminence vertex to the Frankfort plane at the deepest point of the articular fossa or any other horizontal plane (occlusal or palatal) of choice (5) (Figure 6).

The articular eminence has been assessed for its height and for its inclination (steepness). Female patients presented higher eminence height values in two of the three assessed studies, which were conducted using MRI instead of CBCT images. When considering the articular eminence's 

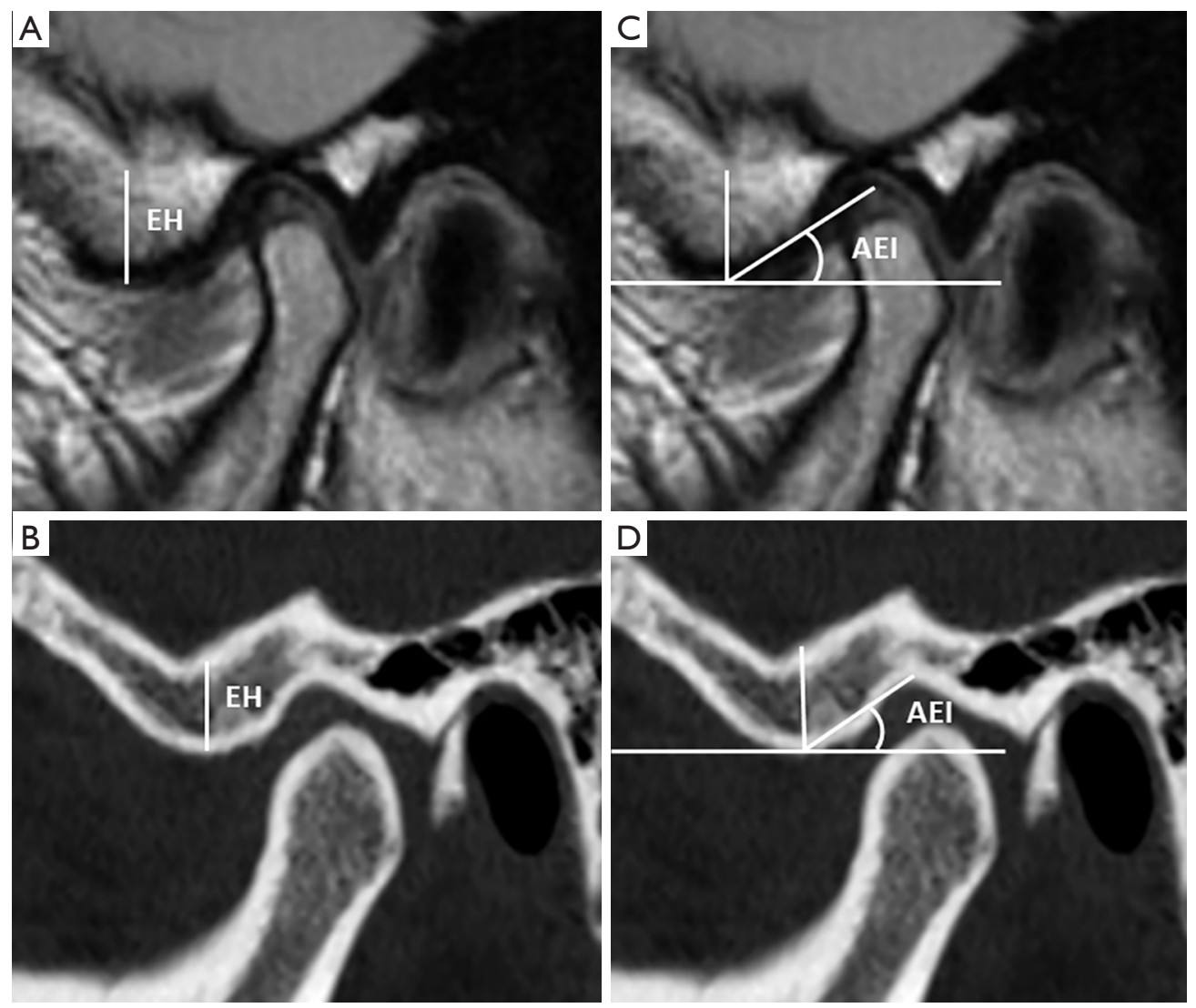

Figure 6 Morphometric assessments of the articular eminence to assess the following morphometric measurements: (A) articular EH on MRI; (B) articular EH on CT; (C) AEI on MRI; (D) AEI on CT. EH, eminence height; AEI, articular eminence inclination.

inclination/steepness the gender difference is not conclusive (Table 3).

\section{Discussion}

The TMJ is one of the most important and differentiated joints of the human body. It is important to understand the TMJ's morphology to distinguish between a normal variant and a pathological condition (36). The different morphological variations of the TMJ components play an important role in understanding the TMJ's normality, function, and potential diseases to provide proper management and treatment (11). Several studies have investigated the relationship between the morphological and morphometric variations of the TMJ associating them with pathological changes according to sex and age groups $(15,20,26,37)$.

The TMJ is constantly remodeling according to the individual's development and adapting according to the non- functional changes that occur in the stomatognathic system. Meng et al. (38) found significant differences between children and adults TMJs, indicating that the skeletal morphology is influenced by age. When establishing agerelated anatomical reference values for the size and shape of the mandibular condyle in children, Karlo et al. (39), concluded that the mandibular condyle presents significant changes in size and shape related to age. As the size of the condyles increases with age, the shape of the condyle tends to change from round to oval on axial view (39).

When the balance between the joint's adaptive capacity and the stresses placed on the joint is lost, dysfunctional remodeling can cause changes in the condyle shape, size, and volume (15). Teeth provide a stable vertical and horizontal relationship between the mandible and the maxilla and provide orientation plans for the anterior and lateral movement of the mandible; thus, tooth loss is an important factor in the condyle morphological alterations (15). In a previous study, the loss of posterior teeth was accompanied 
Table 3 Summary of morphometric measures of the articular eminence in previous studies

\begin{tabular}{|c|c|c|c|c|c|c|c|c|}
\hline \multirow{3}{*}{$\begin{array}{l}\text { Previous } \\
\text { studies }\end{array}$} & \multicolumn{8}{|c|}{ Articular eminence } \\
\hline & \multicolumn{2}{|c|}{ Methodology } & \multicolumn{3}{|c|}{ Articular eminence height (mm) } & \multicolumn{3}{|c|}{ Steepness of the eminence (degrees) } \\
\hline & $\begin{array}{c}\text { Image } \\
\text { Modality }\end{array}$ & $\begin{array}{c}\text { TMJ } \\
\text { Sample Size }\end{array}$ & Male & Female & $\begin{array}{c}\text { Both } \\
\text { Genders }\end{array}$ & Male & Female & $\begin{array}{c}\text { Both } \\
\text { Genders }\end{array}$ \\
\hline Derwich 2020 & СВСТ & 210 & - & - & 8.1 & - & - & \\
\hline Yasa 2018 & СВСТ & 400 & 8.12 & 7.52 & - & - & - & - \\
\hline Rabelo 2017 & MRI & 199 & 6.47 & 6.51 & - & 37.61 & 37.78 & - \\
\hline Sa 2017 & СВСТ & 528 & - & - & - & 39.3 & 37.6 & - \\
\hline Peroz 2011 & MRI & 78 & - & - & 8.8 & - & - & 44.0 \\
\hline
\end{tabular}

Table data were extracted from previously published studies referenced in the table first column. TMJ, temporomandibular joint; CBCT, cone beam computed tomography; MRI, magnetic resonance imaging.

by a significant decrease in the height of the condyle and an increase in the width of the condyle without alteration in its total volume (15).

Some studies have investigated the morphological and morphometric relationship of TMJs with disc displacement using MRI $(5,8,10,40,41)$. MRI is the gold standard for evidencing structural changes, especially in the soft tissues of the TMJ as it can detect the articular disc (8). Peroz et al. (8) found that female patients present disc displacement and combined morphometric changes in the TMJ significantly more frequently than male patients. Male patients appear to have larger and wider TMJ bone structures, what may be one of the reasons for the predominance of TMD in women (5). Women seem to be more affected by TMD due to androgenic hormones; however, men tend to attend their general practitioner later during a condition than women (42). Studies with higher male patients' samples are needed to ensure those findings.

According to Kurita et al. (26), the horizontal condylar angle presented higher values in joints with disc displacement without reduction, which are in accordance with CrusoéRebello et al. (37). Therefore, there is a tendency of increased horizontal condylar angles in TMJs with aggravated internal disorders (37).

The control of the posterior movement of the mandible is significantly affected by the inclination of the articular eminence, which determines the orientation and path of the condyle during the mandible's functional movements (43). Therefore, the articular eminence dictates the path and type of condyle-disc movement. The articular eminence's inclination can influence the range of the condyle's excursion movement (5). Patients with accentuated articular eminences presented wider condyle-disc movement during function, and this exaggerated movement can lead to higher risk of elongating the posterior ligament what can induce disc disorders (44).

The articular eminence morphology and inclination have also been reported as predisposal factors of disc displacement. According to Katsavrias et al. (45), the articular eminence inclination values for adults should vary from $30^{\circ}$ to $60^{\circ}$, and articular eminence inclination values lower than $30^{\circ}$ or higher than $60^{\circ}$ are associate with disc displacement. Rabelo et al. (5), found that higher articular eminence inclination values and condylar excursion angles were associated with disc displacement with reduction, what may indicate that higher articular eminence inclination may be better than lower articular eminence inclination values when considering the possibility of disc recapture (35).

Discrepancies between image modalities measurement techniques are associated with each image modality's unique limitations. CBCT has low contrast depicting soft tissue structures, while MRIs are limited by resolution (14). According to Coombs et al. (14) physical measurements were generally larger than both CBCT-based measurements and MRI-based measurements, with little difference between CBCT-based and MRI-based model measurements. Link et al. (46), found that MRI and CT images are significantly correlated with the corresponding specimen sections and high-resolution MRI performs better in the prediction of trabecular bone structure than CT. Independent on the 
differences in spatial resolution between the different image modalities, there is no significant difference between them when measuring morphometric features of the TMJ.

It is important to stress that CBCT and CT images present higher contrast for bone images and are indicated for TMJ morphometric assessments (47), however, they should be used in retrospective studies, where previous ionizing images were referred and acquired for a specific diagnostic task that would not interfere on the assessment proposed by the study. MRI images are the modality of choice when the study aims to compare morphometric variations of the TMJ with internal disorders (48).

It can be concluded that large, paired samples and longitudinal studies using non-ionizing images are still needed to assess the TMJ morphometric values and its association with internal disorders, age, ethnicity, and gender.

\section{Acknowledgments}

Funding: None.

\section{Footnote}

Peer Review File: Available at https://fomm.amegroups.com/ article/view/10.21037/fomm-20-63/prf

Conflicts of Interest: All authors have completed the ICMJE uniform disclosure form (available at https://fomm. amegroups.com/article/view/10.21037/fomm-20-63/coif). The authors have no conflicts of interest to declare.

Ethical Statement: The authors are accountable for all aspects of the work in ensuring that questions related to the accuracy or integrity of any part of the work are appropriately investigated and resolved.

Open Access Statement: This is an Open Access article distributed in accordance with the Creative Commons Attribution-NonCommercial-NoDerivs 4.0 International License (CC BY-NC-ND 4.0), which permits the noncommercial replication and distribution of the article with the strict proviso that no changes or edits are made and the original work is properly cited (including links to both the formal publication through the relevant DOI and the license). See: https://creativecommons.org/ licenses/by-nc-nd/4.0/.

\section{References}

1. Bag AK, Gaddikeri S, Singhal A, et al. Imaging of the temporomandibular joint: An update. World J Radiol 2014;6:567-82.

2. Talmaceanu D, Lenghel LM, Bolog N, et al. Imaging modalities for temporomandibular joint disorders: an update. Clujul Med 2018;91:280-7.

3. Mendiburu-Zavala C, Camargo-Riqué ME, PeñalozaCuevas R, et al. Tomographic analysis of the temporomandibular joint in patients with arthritis: a case of disease translation in Yucatan, Mexico. Am J Transl Res 2019;11:210-7.

4. Vos LM, Kuijer R, Huddleston Slater JJ, et al. Inflammation is more distinct in temporomandibular joint osteoarthritis compared to the knee joint. J Oral Maxillofac Surg 2014;72:35-40.

5. Rabelo KA, Sousa Melo SL, Torres MGG, et al. Condyle excursion angle, articular eminence inclination, and temporomandibular joint morphologic relations with disc displacement. J Oral Maxillofac Surg 2017;75:938.e1-10.

6. Yale SH, Ceballos M, Kresnoff CS, et al. Some observations on the classification of mandibular condyle types. Oral Surg Oral Med Oral Pathol 1963;16:572-7.

7. Wadhwa S, Kapila S. TMJ disorders: future innovations in diagnostics and therapeutics. J Dent Educ 2008;72:930-47.

8. Peroz I, Seidel A, Griethe M, et al. MRI of the TMJ: morphometric comparison of asymptomatic volunteers and symptomatic patients. Quintessence Int 2011;42:659-67.

9. Razek AAKA, Al Mahdy Al Belasy F, Ahmed WMS, et al. Assessment of articular disc displacement of temporomandibular joint with ultrasound. J Ultrasound 2014;18:159-63.

10. Torres MG, Crusoé-Rebello IM, Rosário M, et al. Morphometric features of the mandibular condyle and association with disk abnormalities. Oral Surg Oral Med Oral Pathol Oral Radiol 2016;121:566-72.

11. Zhang Y, Xu X, Liu Z. Comparison of morphologic parameters of temporomandibular joint for asymptomatic subjects using the two-dimensional and three-dimensional measuring methods. J Healthc Eng 2017;2017:5680708.

12. Klatkiewicz T, Gawriołek K, Pobudek Radzikowska $\mathrm{M}$, et al. Ultrasonography in the diagnosis of temporomandibular disorders: a meta-analysis. Med Sci 
Monit 2018;24:812-7.

13. de Pontes MLC, Melo SLS, Bento PM, Campos PSF, de Melo DP. Correlation between temporomandibular joint morphometric measurements and gender, disk position, and condylar position. Oral Surg Oral Med Oral Pathol Oral Radiol 2019;128:538-42.

14. Coombs MC, Bonthius DJ, Nie X, et al. Effect of measurement technique on TMJ mandibular condyle and articular disc morphometry: CBCT, MRI, and physical measurements. J Oral Maxillofac Surg 2019;77:42-53.

15. Ahmed NF, Samir SM, Ashmawy MS, et al. Cone beam computed tomographic assessment of mandibular condyle in Kennedy class I patients. Oral Radiol 2020;36:356-64.

16. Friedman SN, Grushka M, Beituni HK, et al. Advanced ultrasound screening for temporomandibular joint (TMJ) internal derangement. Radiol Res Pract 2020;2020:1809690.

17. Litko-Rola M, Szkutnik J, Różyło-Kalinowska I. The importance of multisection sagittal and coronal magnetic resonance imaging evaluation in the assessment of temporomandibular joint disc position. Clin Oral Investig 2021;25:159-68.

18. Faber J, Fonseca LM. How sample size influences research outcomes. Dental Press J Orthod 2014;19:27-9.

19. Yasa Y, Akgül HM. Comparative cone-beam computed tomography evaluation of the osseous morphology of the temporomandibular joint in temporomandibular dysfunction patients and asymptomatic individuals. Oral Radiol 2018;34:31-9.

20. Sa SC, Melo SLS, Melo DP, et al. Relationship between articular eminence inclination and alterations of the mandibular condyle: a CBCT study. Braz Oral Res 2017;31:e25.

21. Derwich M, Mitus-Kenig M, Pawlowska E. Temporomandibular joints' morphology and osteoarthritic changes in cone-beam computed tomography images in patients with and without reciprocal clicking - a case control study. Int J Environ Res Public Health 2020;17:3428.

22. Santos KC, Dutra ME, Warmling LV, et al. Correlation among the changes observed in temporomandibular joint internal derangements assessed by magnetic resonance in symptomatic patients. J Oral Maxillofac Surg 2013;71:1504-12.

23. Orhan K, Seki U, Rozylo-Kalinowska I. Diagnostic accuracy of magnetic resonance imaging and clinical signs of temporomandibular joint disorders: a 10-year research update review. Oral Radiol 2017;33:81-91.
24. Paknahad M, Shahidi S, Akhlaghian M, et al. Is Mandibular fossa morphology and articular eminence inclination associated with temporomandibular dysfunction? J Dent (Shiraz) 2016;17:134-41.

25. Al-koshab M, Nambiar P, John J. Assessment of condyle and glenoid fossa morphology using CBCT in South-East Asians. PLoS One 2015;10:e0121682.

26. Kurita H, Ohtsuka A, Kobayashi H, et al. Relationship between increased horizontal condylar angle and resorption of the posterosuperior region of the lateral pole of the mandibular condyle in temporomandibular joint internal derangement. Dentomaxillofac Radiol 2003;32:26-9.

27. Lee PP, Stanton AR, Hollender LG. Greater mandibular horizontal condylar angle is associated with temporomandibular joint osteoarthritis. Oral Surg Oral Med Oral Pathol Oral Radiol 2017;123:502-7.

28. Alomar X, Medrano J, Cabratosa J, et al. Anatomy of the temporomandibular joint. Semin Ultrasound CT MR 2007;28:170-83.

29. de Farias JF, Melo SL, Bento PM, et al. Correlation between temporomandibular joint morphology and disc displacement by MRI. Dentomaxillofac Radiol 2015;44:20150023.

30. Oberg T, Carlsson GE, Fajers CM. The temporomandibular joint. A morphologic study on a human autopsy material. Acta Odontol Scand 1971;29:349-84.

31. Matsumoto K, Kameoka S, Amemiya T, et al. Discrepancy of coronal morphology between mandibular condyle and fossa is related to pathogenesis of anterior disk displacement of the temporomandibular joint. Oral Surg Oral Med Oral Pathol Oral Radiol 2013;116:626-32.

32. Pedullà E, Meli GA, Garufi A, et al. Morphometric evaluation of the temporomandibular joint and the masticatory spaces: the role of high-definition MRI. Minerva Stomatol 2009;58:127-43.

33. Ichikawa J, Hara T, Tamatsu Y, et al. Morphological changes in the internal structure of the articular eminence of the temporal bone during growth from deciduous to early mixed dentition. J Biomech 2007;40:3541-7.

34. Kurita H, Ohtsuka A, Kobayashi H, et al. Is the morphology of the articular eminence of the temporomandibular joint a predisposing factor for disc displacement? Dentomaxillofac Radiol 2000;29:159-62.

35. Hirata FH, Guimarães AS, Oliveira JX, et al. Evaluation of TMJ articular eminence morphology and disc patterns in patients with disc displacement in MRI. Braz Oral Res 
2007;21:265-71.

36. Hegde S, Praveen BN, Shetty SR. Morphological and radiological variations of mandibular condyles in health and diseases: a systematic review. Dentistry 2013;3:154.

37. Crusoé-Rebello IMR, Campos PSF, Rubira IRF, et al. Evaluation of the relation between the horizontal condylar angle and the internal derangement of the TMJ - a magnetic resonance imaging study. Pesqui Odontol Bras 2003;17:176-82.

38. Meng F, Liu Y, Hu K, et al. A comparative study of the skeletal morphology of the temporo-mandibular joint of children and adults. J Postgrad Med 2008;54:191-4.

39. Karlo CA, Stolzmann P, Habernig S, et al. Size, shape and age-related changes of the mandibular condyle during childhood. Eur Radiol 2010;20:2512-7.

40. Bristela M, Schmid-Schwap M, Eder J, et al. Magnetic resonance imaging of temporomandibular joint with anterior disk dislocation without reposition - long-term results. Clin Oral Investig 2017;21:237-45.

41. Rabelo KA, Sousa Melo SL, Torres MGG, et al. Assessment of condyle position, fossa morphology, and disk displacement in symptomatic patients. Oral Surg Oral Med Oral Pathol Oral Radiol 2017;124:199-207.

42. Banks I. No man's land: men, illness, and the NHS. BMJ 2001;323:1058-60.

doi: $10.21037 /$ fomm-20-63

Cite this article as: de Melo DP, Silva DFB, Campos PSF, Dantas JA. The morphometric measurements of the temporomandibular joint. Front Oral Maxillofac Med 2021;3:14.
43. Han S, Shin SM, Choi YS, et al. Morphometric analysis for evaluating the relation between incisal guidance angle, occlusal plane angle, and functional temporomandibular joint shape variation. Acta Odontol Scand 2018;76:287-93.

44. Sharma S, Gupta DS, Pal US, et al. Etiological factors of temporomandibular joint disorders. Natl J Maxillofac Surg 2011;2:116-19.

45. Katsavrias EG, Halazonetis DJ. Condyle and fossa shape in Class II and Class III skeletal patterns: a morphometric tomographic study. Am J Orthod Dentofacial Orthop 2005;128:337-46.

46. Link TM, Vieth V, Stehling C, et al. High-resolution MRI vs multislice spiral CT: Which technique depicts the trabecular bone structure best? Eur Radiol 2003;13:663-71.

47. Ejima K, Schulze D, Stippig A, et al. Relationship between the thickness of the roof of glenoid fossa, condyle morphology and remaining teeth in asymptomatic European patients based on cone beam CT data sets. Dentomaxillofac Radiol 2013;42:90929410.

48. Coombs MC, She X, Brown TR, et al. Temporomandibular joint condyle-disc morphometric sexual dimorphisms independent of skull scaling. J Oral Maxillofac Surg 2019;77:2245-57. 